\title{
Analysis of Black Start of a Microgrid with PV, DG, and BESS
}

\author{
Akhiya Sanal, Pruthiraj Swain, Ashoka Shyamaprasad
}

\begin{abstract}
Different combinations of operating scenarios for a microgrid with distributed energy resources and energy storage system is considered to understand the operation of a microgrid. An operational strategy analysis of a microgrid system consisting of photovoltaics, diesel generator, and battery energy storage system during a black start in islanded mode is considered in this paper. BESS under study consists of a bidirectional converter and a battery system. BESS is assumed to be active as a solution provided in all the scenarios. The various capabilities of BESS in a microgrid system is also discussed. Microgrid system provides reliable power supply and hence black start capability for such a system is essential in keeping intact the advantages of a microgrid. Performing a black start requires a sequential process to be followed to avoid fluctuations in bus voltage, frequency, and protecting the fuses/ contactors from blowing. To black start the system under study, the DC breaker connecting the battery and the bidirectional converter needs to be closed. Closing the DC breaker results in high inrush current from batteries at the DC output of the bidirectional converter. $A D C$ arrangement is envisaged in the battery energy storage system to avoid arcing due to high inrush current.
\end{abstract}

Keywords: Battery Energy Storage System, Black Start, Diesel Generator, Environmental Impact, Microgrid, Photovoltaic, Reliability, Renewables.

\section{INTRODUCTION}

With the progression of the economy, energy demand has increased considerably. Renewable energy such as wind, photovoltaics (PV), hydroelectric, biomass, etc. forming Distributed energy resources (DERs) and energy storage systems (ESS) such as batteries, flywheels, pumped hydro, supercapacitor, etc. have seen a widespread distribution [1] [2]. Fig. 1 shows how renewable energy sources are playing a crucial role in India at present. Distributed generation has received widespread attention and Microgrid (MG) emerged as a result.

The microgrid system consists of low voltage distribution system with DERs together with an ESS and flexible loads. This system can be operated by either connected to the grid or off-grid. Microgrids helps in secure and reliable access to power [3] [4]. During a contingency, microgrid disconnects itself from the main grid and operates in an islanded mode with uninterrupted supply to load using its DERs [5] [6].

Revised Manuscript Received on March 5, 2020.

* Correspondence Author

Akhiya Sanal*, R\&D Associate Engineer, Power Grids-Grid Automation, ABB India Limited, Bengaluru, India. Email: akhiya.sanal@in.abb.com

Pruthiraj Swain, R\&D Engineer, Power Grids-Grid Automation, ABB India Limited, Bengaluru, India. Email: pruthiraj.swain@in.abb.com

Ashoka Shyamaprasad, Technical Product Manager, Power Grids-Grid Automation, ABB India Limited, Bengaluru, India. Email: ashoka.shyamaprasad@in.abb.com
Stabilizing the microgrid system by maintaining the voltage and frequency through an efficient control system is the main key factor that distinguishes microgrid from the distributed network. Several papers have discussed various control algorithms to maintain the bus voltage to stabilize the microgrid system [3], [7]-[9].

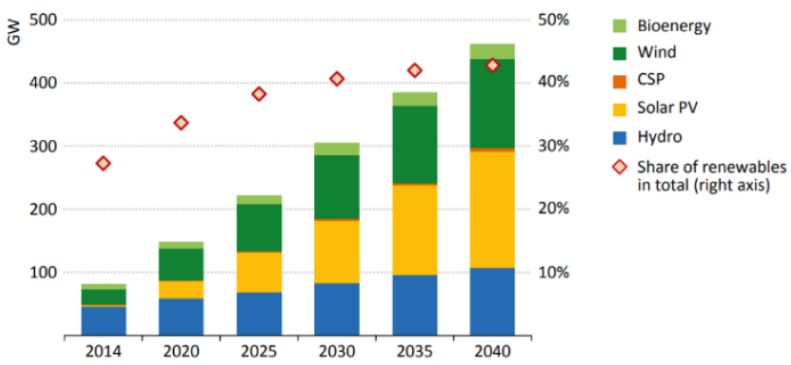

Note: $\mathrm{GW}=$ gigawatts.

Fig. 1.Renewable-based power generation capacity in India [2]

The blackout of the microgrid will have a huge impact on the system as renewable energy goes unutilized and it affects the loads. Restoring the system helps to reduce the interruption time and economic loss [10] [11]. The process of restoring the electric power or distributed system to operate without relying on the external electric power system is called the black start (BS) of microgrid [12]. Performing black start helps in restoring the system back online to the normal stable operating condition [13] [14]. It also helps in maximizing the system reliability and reduces the environmental impact. The system must be capable of black start, i.e., the system should have enough startup power capacity. Carrying out black start without enough power capability leads to fluctuations in bus voltage and frequency [13], [15]-[18].

Different black start restoration sequence for microgrids like series and parallel restoration based on the restoration time and its comparison is discussed in [10], [18]-[20]. Parallel restoration strategy has a complex design and it is difficult to connect the subsystem to the microgrid as there will be high impulse current when the subsystem is connected. But the available method helps in fast restoration of the system [21]-[23]. The serial restoration process has a simple hardware and software design which takes more time for restoration [24] [25].

The general content flow of the document is arranged as follows. Section 2 explains the system review where the microgrid system under study is discussed. Section 3 presents the various operating scenarios of the system. Section 4 discusses the black start strategy and section 5 is the conclusion with the main takeaway points.

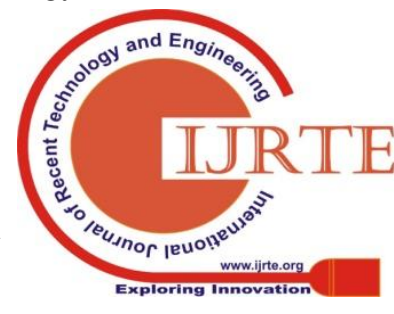




\section{SYSTEM REVIEW}

The system under study consists of Photovoltaic (PV) system, Grid, diesel generator (DG), and battery-based energy storage system (BESS). The typical arrangement of a Microgrid system is represented as follows in Fig. 2. The BESS is connected to the AC bus via a transformer which steps down/ step up the grid voltage to the required voltage of the bi-directional converter system (BDC) [20]. The BDC system allows to store or access energy when it is needed in the battery system. BDC system usually has the capability of load leveling, grid stabilizing, grid loss detection, power quality improvement, and grid compliance for renewable and generation systems.

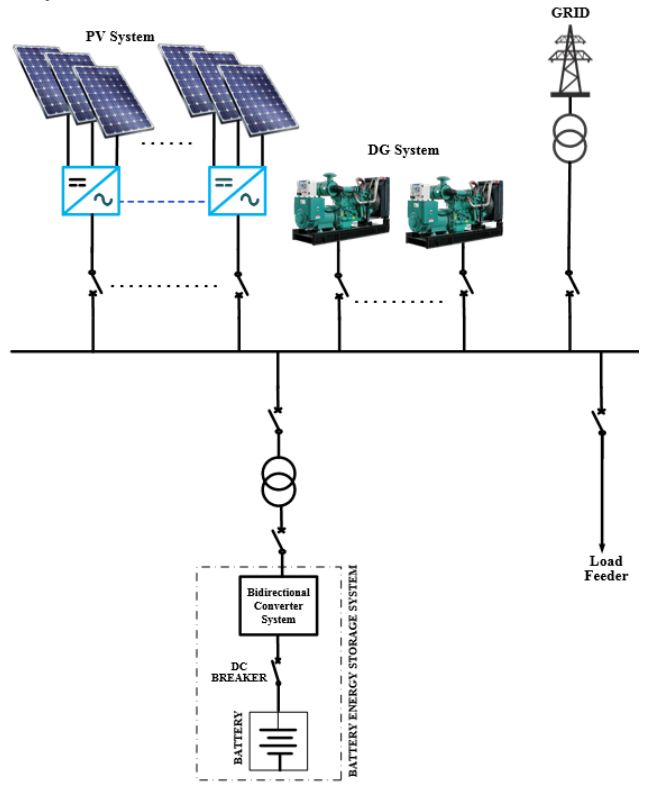

Fig. 2.Typical arrangement of Microgrid System BESS system has the following capabilities -

\section{A. Frequency/ Voltage Stabilizing}

Frequency/ Voltage stabilizing is maintaining a steady frequency and voltage to keep the microgrid balanced and operational as shown in Fig. 3 and to protect sensitive loads [26]. Recurrent power generation from DERs, along with variable loads cause fluctuations from the nominal frequency in the grid. BESS system can maintain the stability of the system [27].

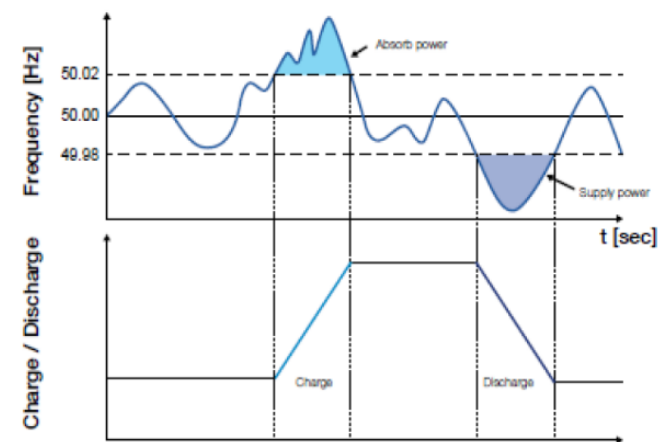

Fig. 3. MG application- Frequency/ Voltage Stabilizing [27]

\section{B. Spinning reserve}

It is the excess generation capacity available to respond to sudden load changes [28]. In order to provide the most important contingency reserve, the BESS system is maintained at a charge level, as shown in Fig.4, to respond to

an outage event.

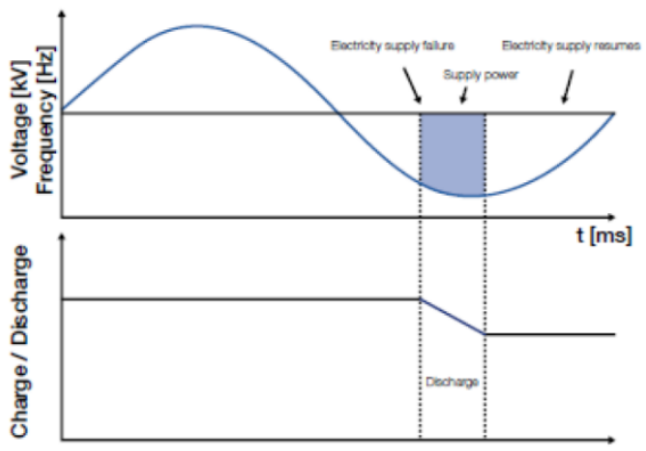

Fig. 4. MG application- Spinning reserve [27]

C. STATCOM (Static reactive power compensation)

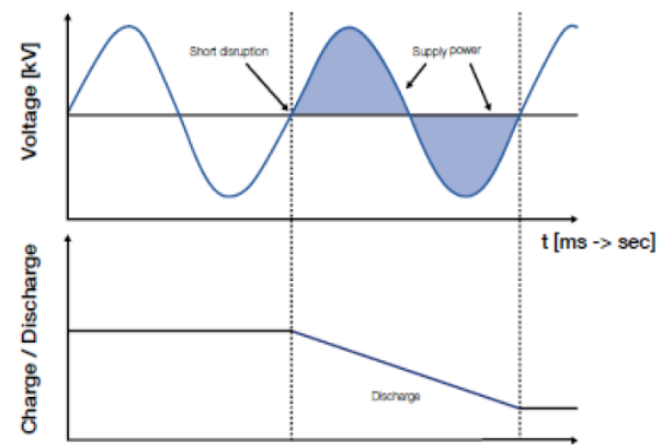

Fig. 5. MG application- STATCOM [27]

It provides dynamic voltage support to the microgrid system. STATCOM application as per Fig. 5 in a BESS system helps in suppressing the voltage fluctuations by the exchange of active and reactive power [29] [30].

\section{Seamless transition between islanded and grid-connected states}

Seamless transition between grid connected and off-grid connection without loss of power to the microgrid loads is possible as shown in Fig. 6. This application helps in supporting weak grids and improves the reliability of the overall system [31].

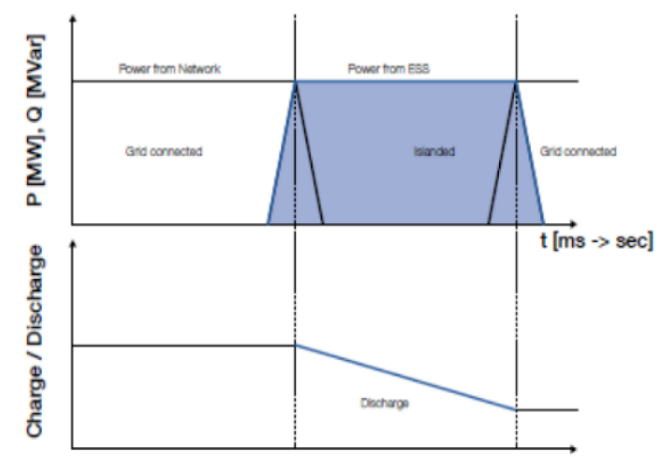

Fig. 6. MG application- Seamless transition [27]

\section{E. Standalone operation}

It allows the microgrid to operate as a standalone grid. The system can operate and maintain stability in the absence of the grid. BESS system can generate the system voltage and frequency [32]. Fig. 7 shows an example of the application. 


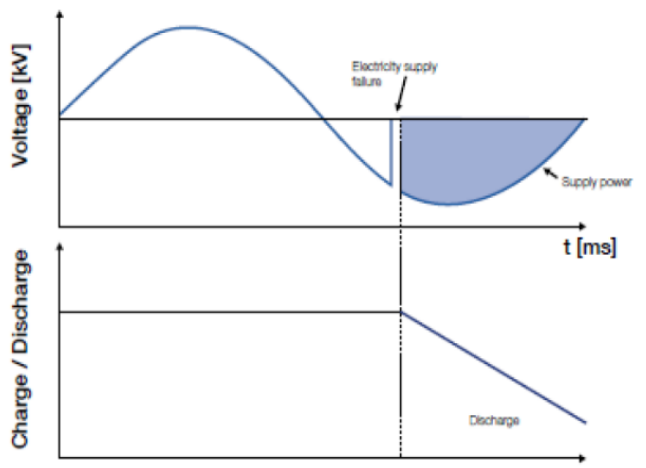

Fig. 7. MG application- Standalone operation [27]

\section{F. Smoothing}

This operation indicates the management of fluctuations of renewable energy sources or sudden load changes by smoothing the power to a defined rate as shown in Fig. 8. BESS system corrects the output to control the voltage fluctuations and power swings on the grid [33].

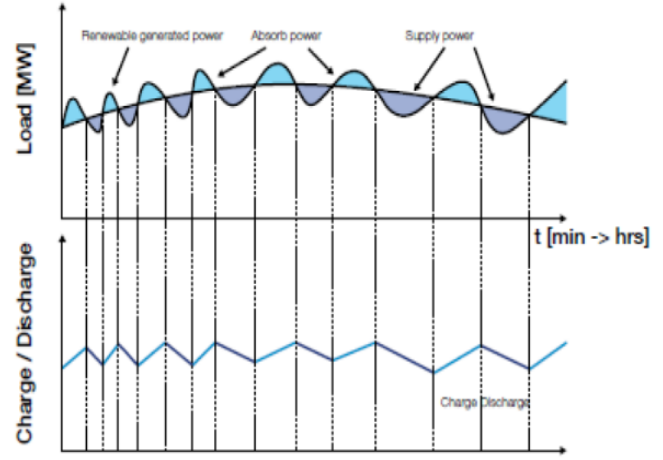

Fig. 8. MG application- Solar/Wind Smoothing [27]

\section{G. Peak Shaving}

This application helps in managing the peak load using storage or dispatchable generators. It helps in reducing the consumption during peak demand by storing the excess energy as shown in Fig. $9 \&$ thus saving cost during maximum demand on utility [34] [35].

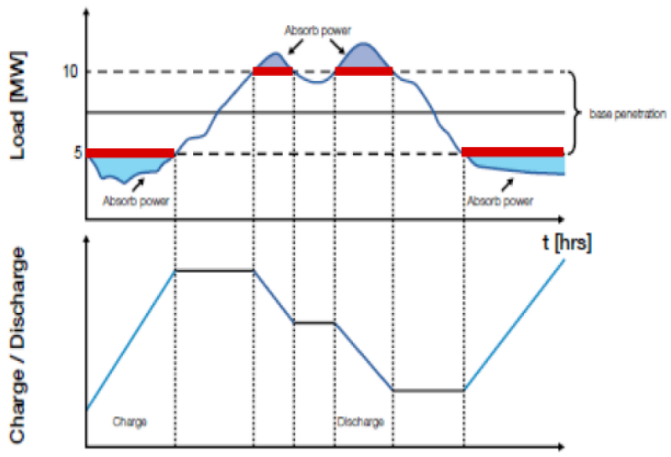

Fig. 9. MG application- Peak Shaving [27]

\section{H. Load/generation Shifting}

Load and generation capacity-shifting application helps to achieve long-term energy consumption goals. Power is stored during excess generation and utilizes when load demand exceeds generation as shown in Fig. 10 [35] [36].

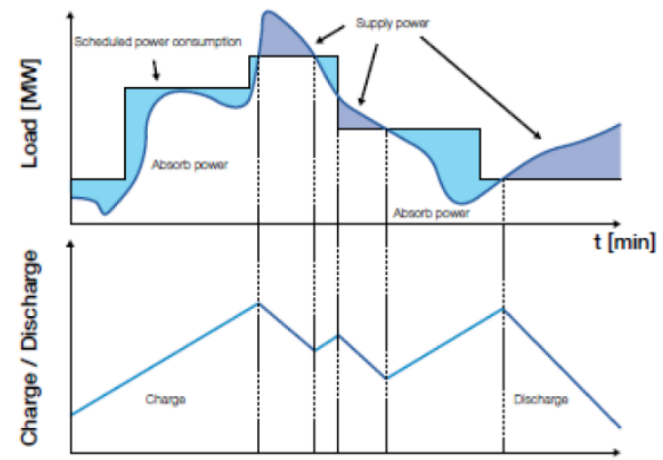

Fig. 10. MG application- Load/generation Shifting [27]

Thus, by installing a BESS in a microgrid will maximize the system reliability, provides uninterrupted power supply, reduces the effect on the environment by maximizing the renewable energy penetration, resulting in fuel and associated cost savings, and hence fuel independence.

\section{OPERATING SCENARIOS}

To analyze the system, different operating scenarios listed in Table. I. are considered.

Table- I: Various Operating Scenarios

\begin{tabular}{|c|c|c|c|c|}
\hline Scenario & Grid & DG & PV & BESS \\
\hline 1 & $\checkmark$ & $\checkmark$ & $\checkmark$ & $\checkmark$ \\
\hline 2 & $x$ & $\checkmark$ & $\checkmark$ & $\checkmark$ \\
\hline 3 & $x$ & $x$ & $\checkmark$ & $\checkmark$ \\
\hline 4 & $x$ & $\checkmark$ & $x$ & $\checkmark$ \\
\hline 5 & $\checkmark$ & $x$ & $\checkmark$ & $\checkmark$ \\
\hline 6 & $\checkmark$ & $x$ & $x$ & $\checkmark$ \\
\hline 7 & $\checkmark$ & $\checkmark$ & $x$ & $\checkmark$ \\
\hline 8 & $x$ & $x$ & $x$ & $\checkmark$ \\
\hline
\end{tabular}

A. Scenario 1 - Grid, DG, PV and BESS active

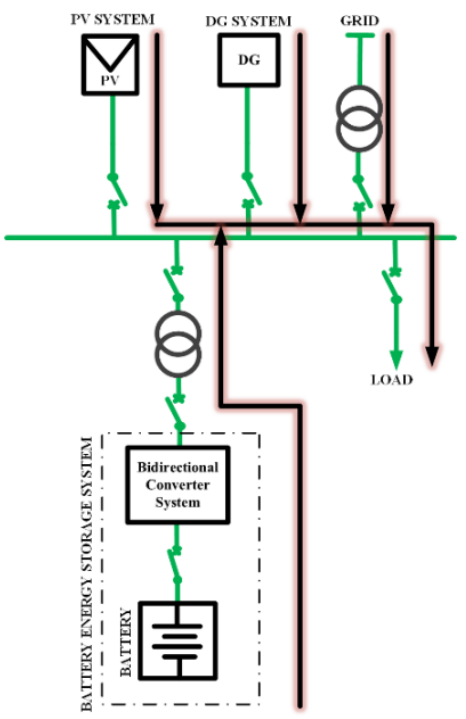

Fig. 11. Load can be fed by the grid, DG, PV, and BESS

This scenario is referred to as the reference scenario where all the sources i.e. grid, DG, PV, and BESS are active. The microgrid system starts in grid-connected mode. The BESS system would run in parallel with the grid and remain in idle mode. The grid determines the voltage and frequency reference for the PV system. 
The grid and the PV system supply the loads. BESS provides reactive power to keep the voltage within the defined boundaries whenever the voltage falls. Similarly, BESS consumes the reactive energy to control the voltage for overvoltage circumstances. When the PV generation is higher than the demand, the batteries in the BESS system is charged up to a specified maximum State of Charge (SoC) limit. Fig. 11 shows the arrangement and the flow of power from the sources.

\section{B. Scenario 2 - Islanded mode}

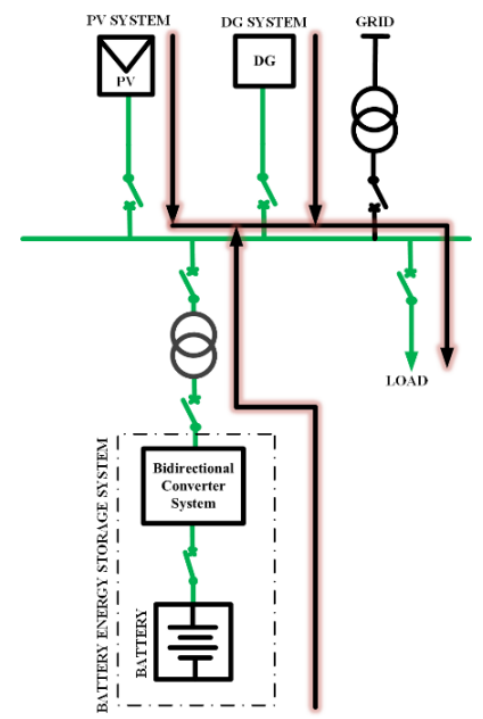

Fig. 12. Load can be fed by DG, PV, and BESS

The microgrid system sets to ooperate in the islanded mode as shown in Fig. 12. To start the system, PV inverter requires voltage and frequency reference. BESS system will be online in virtual generator mode (VGM) and controls the voltage and frequency. The PV system shares the load with BESS and DG, with the battery charging/ discharging as the PV output power fluctuates. In case of excess power requirement, BESS system discharges to meet the load up to the specified minimum limit of SoC $\left(\mathrm{SoC}_{\mathrm{MIN}}\right)$. The output of the DG is limited to load demand.

\section{Scenario 3 - DG inactive in islanded mode}

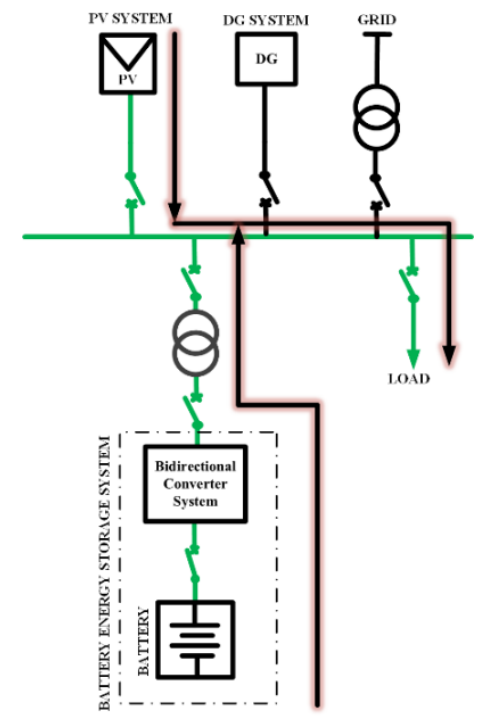

Fig. 13. Load can be fed by PV and BESS

In this scenario, DG is assumed to be in the inactive mode and the microgrid system is set out to be in islanded mode of operation. BESS system operates in VGM mode and dictates the voltage and frequency reference for the PV inverter. PV inverter shares the load with the BESS system. If the battery SoC reaches the minimum $\mathrm{SoC}$ set limit $\left(\mathrm{SoC}_{\mathrm{MIN}}\right)$, then the output power is maintained at $0 \mathrm{~kW}$ and $\mathrm{PV}$ output is regulated to supply load. Fig. 13 shows the system where the load is fed only by PV and BESS as discussed in scenario 3.

\section{Scenario 4 - PV inactive in islanded mode}

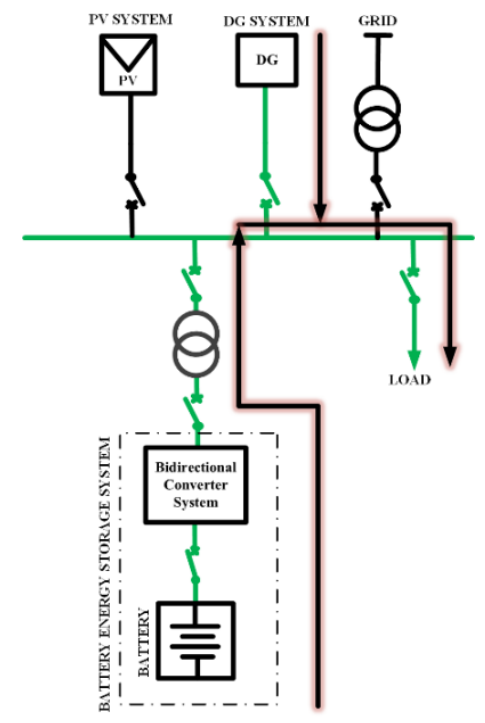

Fig. 14. Load can be fed by DG and BESS

In this scenario, PV system is assumed to be inactive \& the mode of operation of Microgrid system is in Islanded mode, as shown in Fig. 14. The load is fed by BESS system up to the minimum set limit of SoC. After SoC $<\mathrm{SoC}_{\mathrm{MIN}}$, loads are fed by DG. The battery will be charged by DG to the minimum specified $\mathrm{SoC}$ rate $\left(\mathrm{SoC}_{\mathrm{MIN}}\right)$. $\mathrm{DG}$ output is restricted to the load demand during the operating scheme. This case can be treated as scenario 2 once the PV system comes online.

\section{E. Scenario 5 - DG inactive in grid-connected mode}

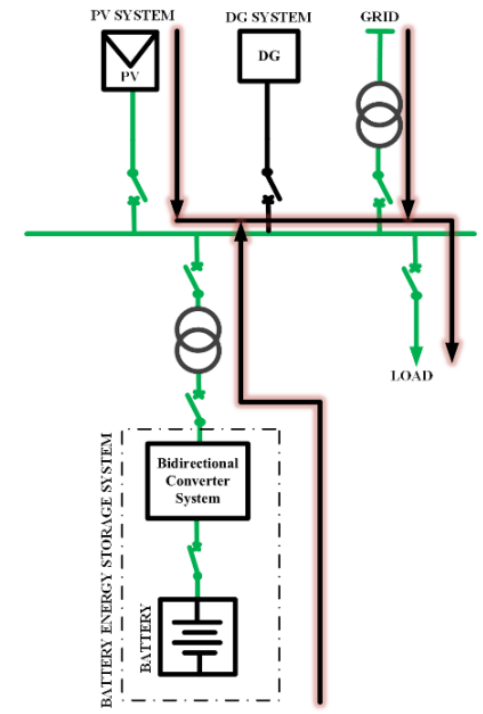

Fig. 15. Load can be fed by Grid, PV and BESS

DGs are assumed to be inactive in this scenario. Grid forms the voltage \& frequency references for the PV system. The load can be met by the grid, PV and BESS. The excess generation is used to charge the battery system up to the maximum set SoC level. In this scenario, DGs are

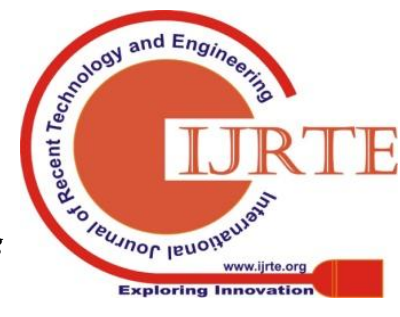


presumed to be inactive. Grid forms the PV system's voltage and frequency reference. The grid, PV and BESS can meet the load. The surplus generation is used up to the maximum specified SoC point for charging the battery system. Fig. 15 shows the flow of power during scenario 5 .

\section{F. Scenario 6 - DG and PV inactive in grid-connected mode}

Fig. 16 shows the scenario where DG and PV are inactive and the microgrid system is grid connected. The load is met from the grid and BESS. BESS system is getting charged from the surplus power availability from the grid. During the daytime, the conditions are the same as scenario 5 as PV becomes active.

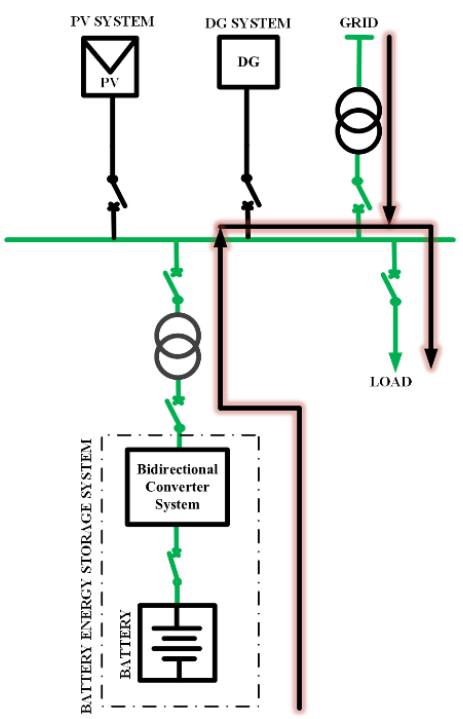

Fig. 16. Load can be fed by Grid and BESS G. Scenario 7 - PV inactive in grid-connected mode

This scenario occurs during night time when PV is inactive. The load can be fed by the grid, DG, and BESS as shown in Fig. 17. The BESS system can discharge up to $\mathrm{SoC}_{\mathrm{MIN}}$ to feed the load when in demand. This scenario can be a reference scenario (scenario 1) during the daytime.

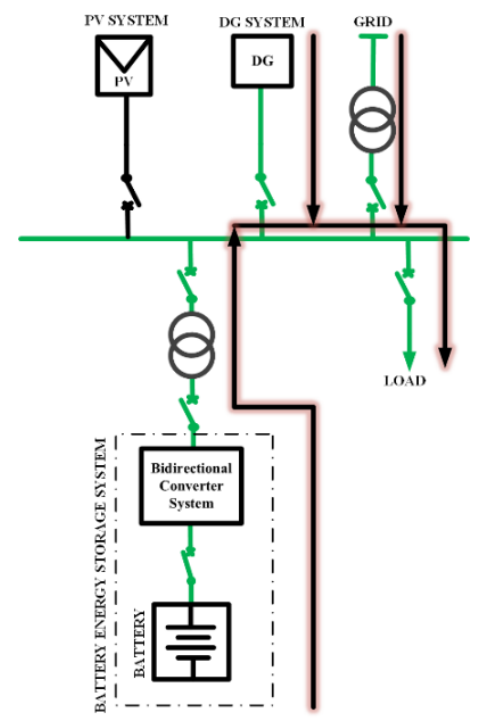

Fig. 17. Load can be fed by Grid, DG and BESS

\section{H. Scenario 8 - DG and PV inactive in islanded mode}

This is the worst-case scenario where DG and PV are inactive, and the operation mode of microgrid system is in islanded mode, as shown in Fig. 18. The BESS system meets the entire load up to $\mathrm{SoC}_{\mathrm{MIN}}$. On reaching the minimum set point of SoC, the system will shut down and blackout occurs. The DC circuit breaker between the battery system and the $\mathrm{BDC}$ system opens to avoid a further reduction in SoC level due to the feeding of residual loads. During daytime when PV becomes active, the operating scenario shifts to scenario 3 .

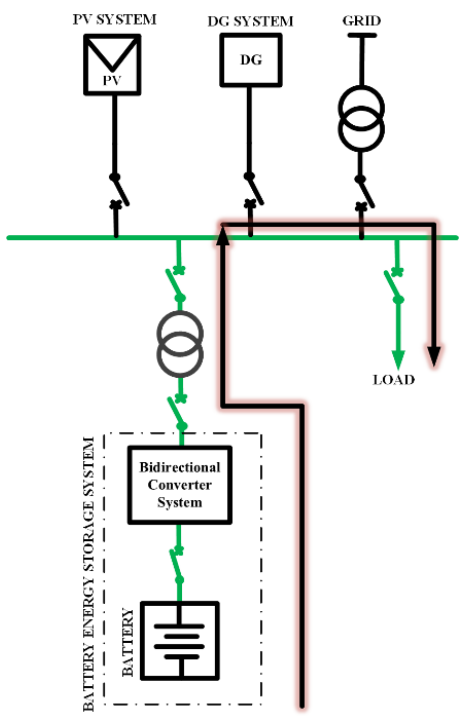

Fig. 18. Load can only be fed by BESS

\section{BLACK START}

In the case of scenario 8 , the microgrid system can be operated only when PV comes online as the battery has reached the minimum set $\mathrm{SoC}$ level $\left(\mathrm{SoC}_{\mathrm{MIN}}\right)$. During daytime, in order to start the microgrid system, PV inverter requires voltage and frequency reference, since it is islanded mode of operation. For the baseline generation, BESS needs to operate in VGM mode. The DC circuit breaker present between the BDC and battery should be closed to bring the system online. When initially connecting a battery to the BDC, there will be chances of high inrush current as the capacitor at the DC output of BDC will charge up to the battery voltage rapidly (capacitor acts as short circuit initially).

A DC arrangement consisting of resistors can be installed in parallel with the DC breaker (as shown in Fig. 19) to suppress the charging current without limiting the operating current. This resistor arrangement slowly charges the capacitor before closing the contactor. Without this resistor, closing the contactor would generate a large amount of inrush current resulting in arc-flash at the contacts. It also helps to start the system with low SoC. Once the BDC DC output reaches the battery voltage, the DC breaker can be safely closed. By this arrangement, most of the BESS system is capable to black start the overall system once the DC breaker is closed. The system can be turned ON and operates in VGM mode to establish voltage and frequency reference for the PV inverter. 

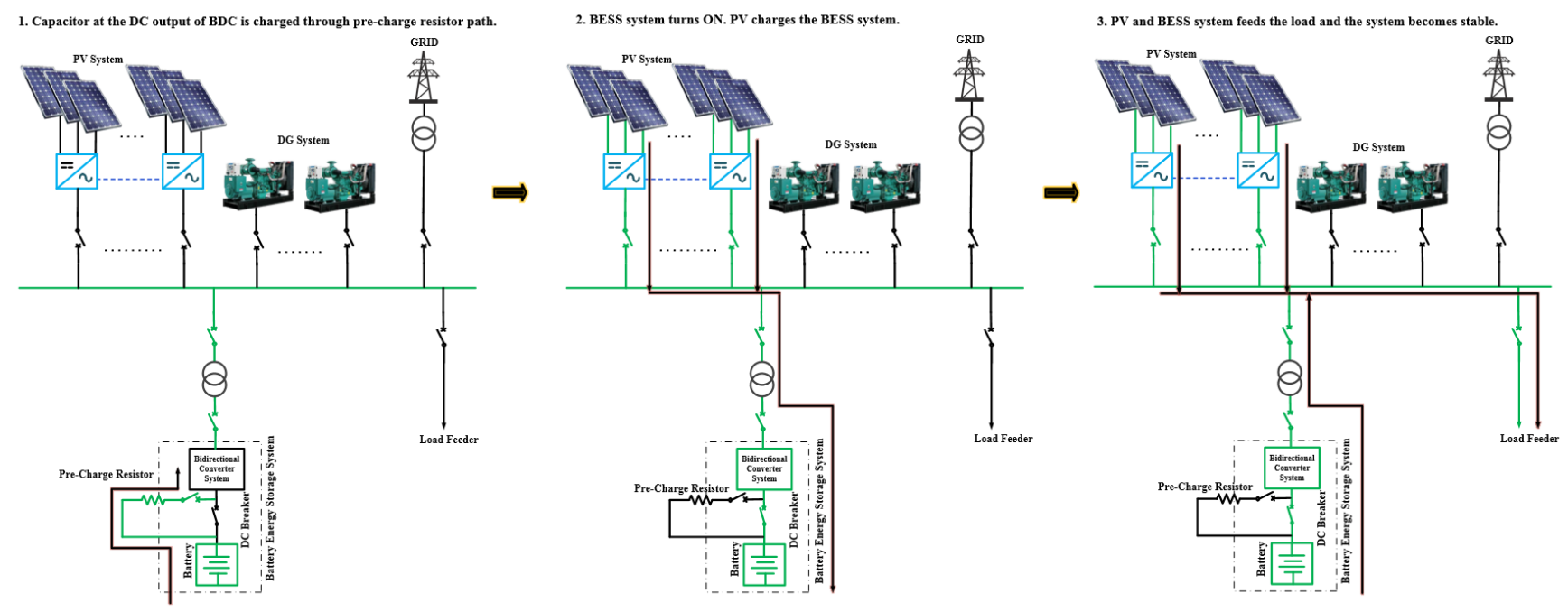

Fig. 19. The sequence of operation of the microgrid system during black start

\section{A. Sequence of Operation}

Before performing black start, the following pre-requisites need to be ensured -

1. No critical alarms are existing in the system,

2. Faults are cleared in the system,

3. AC circuit breaker between the BESS system and grid is closed, and

4. Battery $\mathrm{SoC}>$ Critical low charge level $\left(\mathrm{SoC}_{\mathrm{MIN}}\right)$.

If the $\mathrm{AC}$ circuit breaker is open, the close-up sequence automatically closes it before starting the BDC.

Fig. 19 shows the sequence of operation of the BESS system during black start.

The following are the sequence of black start operation of a microgrid system -

1. DC breaker present between the BDC and battery should be closed to connect the battery system to the BDC. The DC capacitor is charged up to battery voltage via resistor arrangement before closing the DC breaker as shown in Fig. 19.

2. During day time when PV becomes active, the battery system starts getting charged.

3. Once the battery reaches a safe operating SoC limit, PV and BESS system can together feed the load.

A similar sequence of operation is implemented in [10] and the results obtained are shown in Fig. 20. which indicates that the system becomes stable. Upu(p.u.) and f(p.u.) are the system voltage and system frequency respectively in per unit, $\mathrm{P}(\mathrm{kW})$ and $\mathrm{Q}(\mathrm{kVAr})$ are the active and reactive power respectively).

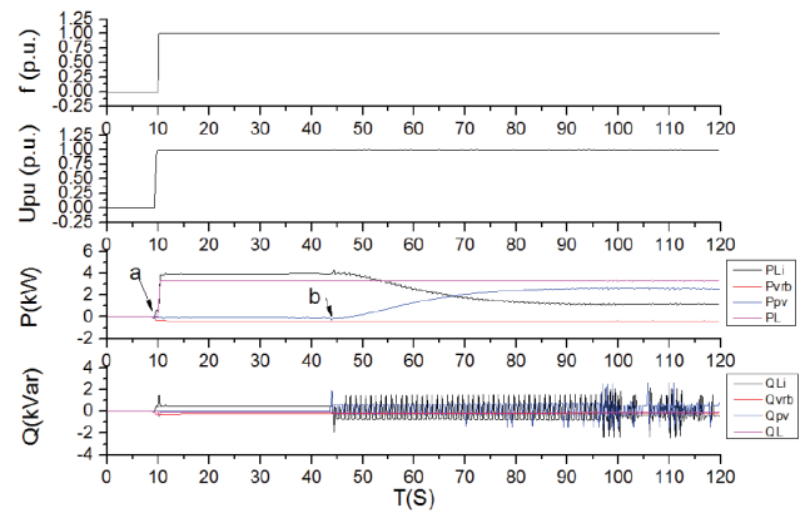

BESS with its black start capability helps in system restoration, maximizes the system reliability, reduces environmental impact and provides grid services. By restoring the system, interruption time and economic losses can be improved, and renewable energy can be utilized to the maximum [10] [24] [37] [38].

Table- II: Comparison between BESS with BS And BESS without BS feature

\begin{tabular}{|c|c|c|}
\hline Application & BESS without BS & BESS with BS \\
\hline Restoration time & High & Low \\
\hline Reliability & Medium & High \\
\hline Network Stability & Low & High \\
\hline Renewable penetration & Medium & High \\
\hline Environmental Impact & High & Low \\
\hline System Complexity & Low & High \\
\hline Ease of $\mathrm{O} \& \mathrm{M}^{(1)}$ & High & Low \\
\hline Carbon footprint $^{(1)(2)}$ & High & Low \\
\hline
\end{tabular}

(1) If DG is used in the absence of grid

(2) Space constraints for DG installation

\section{CONCLUSION}

In this paper, different operating scenarios of a microgrid system with PV, DG, and BESS in grid-connected and islanded mode is analyzed qualitatively. The worst-case scenario i.e. when PV, DG, and grid are inactive is considered where BESS is the primary source of energy. The operational strategy has been discussed and it is found that during this condition, the BESS system becomes inactive when the battery reaches minimum operating $\mathrm{SoC}$ level and the DC breaker between the BDC and battery system opens to prevent deep discharge of the battery system. To black start the system when PV becomes active (during day-time), a DC arrangement is connected across the breaker to avoid the inrush current and the DC breaker can be closed safely without any risk associated. BESS system operates in VGM and establishes voltage and frequency reference to start the PV inverter. Hence, the system becomes stable and can start feeding the load. 


\section{REFERENCES}

1. R. H. Lasseter, "Smart distribution: Coupled microgrids," Proc. IEEE, vol. 99, no. 6, pp. 1074-1082, Jun. 2011.

2. International Energy Agency, "India Energy Outlook," tech. rep., 2015.

3. H. R. Pota, "Droop control for islanded microgrids," 2013 IEEE Power \& Energy Society General Meeting, Vancouver, BC, 2013, pp. $1-4$.

4. Eduard Bullich-Massagué, Francisco Díaz-González, Mònica Aragüés-Peñalba, Francesc Girbau-Llistuella, Pol Olivella-Rosell, Andreas Sumper, "Microgrid clustering architectures", Applied Energy, Volume 212, 2018, Pages 340-361,ISSN 0306-2619

5. D. Salomonsson, L. Soder and A. Sannino, "An Adaptive Control System for a DC Microgrid for Data Centers," in IEEE Transactions on Industry Applications, vol. 44, no. 6, pp. 1910-1917, Nov.-dec. 2008.

6. Khorsandi, Amir, Mojtaba Ashourloo, and Hossein Mokhtari. "A decentralized control method for a low-voltage DC microgrid." IEEE Transactions on Energy Conversion 29.4 (2014): 793-801

7. A. Sanal, V. Mohan, M. R. Sindhu, and S. K. Kottayil, "Real-time energy management and bus voltage droop control in solar powered standalone DC microgrid," 2017 IEEE Region 10 Symposium (TENSYMP), Cochin, 2017, pp. 1-6.

8. Q. Oliveira, A. C. Zambroni de Souza, A. B. Almeida, M. V. Santos, B. I. L. Lopes, and D. Marujo, "Microgrid management in emergency scenarios for smart electrical energy usage," 2015 IEEE Eindhoven PowerTech, Eindhoven, 2015, pp. 1-6.

9. P. H. Nguyen, M. M. Viyathukattuva Mohamed Ali, Francisco M. Portelinha, Paulo F. Ribeiro, J. F. G. Cobben, Microgrids Design and Implementation, pp. 217, 2019.

10. Z. Xu, P. Yang, Q. Zheng and Z. Zeng, "Study on black start strategy of microgrid with PV and multiple energy storage systems," 2015 18th International Conference on Electrical Machines and Systems (ICEMS), Pattaya, 2015, pp. 402-408

11. Y. Zhao, Z. Lin, Y. Ding, Y. Liu, L. Sun and Y. Yan, "A Model Predictive Control Based Generator Start-Up Optimization Strategy for Restoration With Microgrids as Black-Start Resources," in IEEE Transactions on Power Systems, vol. 33, no. 6, pp. 7189-7203, Nov. 2018.

12. M. Shahidehpour, W. F. Tinney, and F. Yong, "Impact of Security on Power Systems Operation," Proceedings of the IEEE, vol. 93, pp. 2013-2025, 2005.

13. Dong, X.Y. The Study on Black Start for District Power Network; Zhejiang University: Hangzhou, China, 2012

14. V. K Agrawal, R. K. Porwal, Rajesh Kumar, Vivek Pandey, "Mock Blackstart Drills - An Excellent Learning Experience for Power System Operators", CBIP $5^{\text {th }}$ International Conferenc eon Power System Protection and Automation, 6-9 Dec 2010.

15. X. Wu, S. Shi, X. Wang, C. Duan, T. Ding and F. Li, "Optimal black start strategy for microgrids considering the uncertainty using a data-driven chance constrained approach," in IET Generation, Transmission \& Distribution, vol. 13, no. 11, pp. 2236-2248, 462019

16. J. W. Feltes and C. Grande-Moran, "Black start studies for system restoration," 2008 IEEE Power and Energy Society General Meeting Conversion and Delivery of Electrical Energy in the 21st Century, Pittsburgh, PA, 2008, pp. 1-8

17. Eto, J. H. "Final report on the August 14, 2003 blackout in the United States and Canada: causes and recommendations." US-Canada Power System Outage Task Force, Washington, DC and Ottawa Canada (2004).

18. Xin, K.; Wu, X.C.; He, S.Z. Review on the blackout of power systems and discussion on its security lessons and related countermeasures. South. Power Syst. Technol. 2013, 7, 32-38.

19. Wu, Z.; Zhang, D.; Lin, X. Research on the Extended Black-Start Scheme of Power System with Microgrid. IJREAT Int. J. Res. Eng. Adv. Technol. 2016, 4, 203-215.

20. Meng, Q \& Mu, Longhua \& Xu, X \& Zhu, G. (2014). Black-start strategy of isolated microgrid. Dianli Zidonghua Shebei/Electric Power Automation $\quad$ Equipment. $\quad 34 . \quad 59-64$ 10.3969/j.issn.1006-6047.2014.03.010.

21. Resende, F. O., Gil, N. J. and Lopes, J. A. (2011), Service restoration on distribution systems using Multi-MicroGrids. Euro. Trans. Electr. Power, 21: 1327-1342

22. Ionela Prodan, Enrico Zio, A model predictive control framework for reliable microgrid energy management, International Journal of Electrical Power \& Energy Systems, Volume 61, 2014, Pages 399-409

23. C. Gouveia, J. Moreira, C. L. Moreira and J. A. Peças Lopes, "Coordinating Storage and Demand Response for Microgrid
Emergency Operation," in IEEE Transactions on Smart Grid, vol. 4, no. 4, pp. 1898-1908, Dec. 2013.

24. Li, J.; Su, J.; Yang, X.; Zhao, T. Study on microgrid operation control and black start. In Proceedings of the 2011 4th International Conference on Electric Utility Deregulation and Restructuring and Power Technologies (DRPT), Weihai, China, 6-9 July 2011; pp 1652-1655.

25. D. Q. Oliveira, A. C. Zambroni de Souza, A. B. Almeida, M. V. Santos, B. I. L. Lopes and D. Marujo, "Microgrid management in emergency scenarios for smart electrical energy usage," 2015 IEEE Eindhoven PowerTech, Eindhoven, 2015, pp. 1-6.

26. W. Liu, W. Gu and Bo Zhao, "A novel multi-agent based control approach for frequency stabilization of islanded microgrids," IEEE PES ISGT Europe 2013, Lyngby, 2013, pp. 1-5.

27. https://new.abb.com/distributed-energy-microgrids/applications

28. NREL, "Operating Reserve and Variable Generation" [Online], Available from: http://www.nrel.gov/docs/fy11osti/51978.pdf, 2011.

29. Y. Ge, W. Du and T. Littler, "Applying STATCOM/BESS stabilizers in a real large-scale power system," 2nd IET Renewable Power Generation Conference (RPG 2013), Beijing, 2013, pp. 1-4.

30. Z. Yang, C. Shen, L. Zhang, M. L. Crow and S. Atcitty, "Integration of a Statcom and battery energy storage," 2001 Power Engineering Society Summer Meeting. Conference Proceedings (Cat. No.01CH37262), Vancouver, BC, Canada, 2001, pp. 1798 vol.3-

31. C. Wanichrojanarat and P. Wirasanti, "Control Strategy for Seamless Transition of Microgrid Using Battery Energy Storage System," 2018 53rd International Universities Power Engineering Conference (UPEC), Glasgow, 2018, pp. 1-6

32. F. Dubuisson, M. Rezkallah, A. Chandra and M. Tremblay, "Control of a New Standalone Microgrid Configuration," 2018 IEEE Canadian Conference on Electrical \& Computer Engineering (CCECE), Quebec City, QC, 2018, pp. 1-4.

33. M. Baun, M. A. Awadallah and B. Venkatesh, "Implementation of load-curve smoothing algorithm based on battery energy storage system," 2016 IEEE Canadian Conference on Electrical and Computer Engineering (CCECE), Vancouver, BC, 2016, pp. 1-5.

34. T. H. Mehr, M. A. S. Masoum and N. Jabalameli, "Grid-connected Lithium-ion battery energy storage system for load leveling and peak shaving," 2013 Australasian Universities Power Engineering Conference (AUPEC), Hobart, TAS, 2013, pp. 1-6.

35. Q. Xu, Y. Ding, Q. Yan, A. Zheng and P. Du, "Day-Ahead Load Peak Shedding/Shifting Scheme Based on Potential Load Values Utilization: Theory and Practice of Policy-Driven Demand Response in China," in IEEE Access, vol. 5, pp. 22892-22901, 2017.

36. G. Bao, C. Lu, Z. Yuan and Z. Lu, "Battery energy storage system load shifting control based on real-time load forecast and dynamic programming," 2012 IEEE International Conference on Automation Science and Engineering (CASE), Seoul, 2012, pp. 815-820.

37. Xu, Zhirong, Yang, Ping, Zeng, Zhiji, Peng, Jiajun and Zhao, Zhuoli, (2016), Black Start Strategy for PV-ESS Multi-Microgrids with Three-Phase/Single-Phase Architecture, Energies, 9, issue 5, p. 1-14.

38. Wang, J., Mu, L., Zhang, F., \& Zhang, X. (2018). A Parallel Restoration for Black Start of Microgrids Considering Characteristics of Distributed Generations. Energies, 11(1),1

\section{AUTHORS PROFILE}

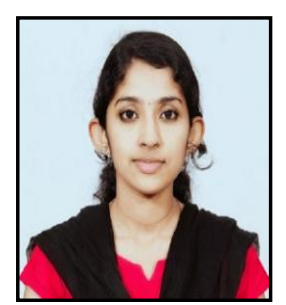

Akhiya Sanal received her Master's degree in Power Electronics from Amrita Vishwa Vidyapeetham, Tamil Nadu, India in 2017 and Bachelor's degree from Amrita School of Engineering, Kerala, India in 2014. She joined ABB India Limited, Bangalore, India in 2017 as an R\&D Associate Engineer in Microgrid and Distributed Generation department focusing on the safety and standardization of Battery Energy Storage Systems. Her research interest includes Power Electronics applications in renewable energy, functional safety and optimization of Battery Energy Storage Systems and Control System Design for Power Converters. 


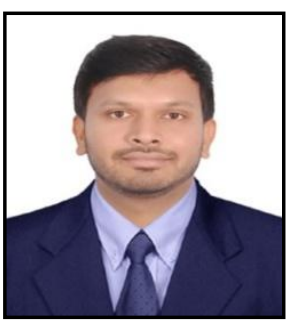

Pruthiraj Swain received his Master's degree in Power \& Energy Systems from National Institute of Technology, Karnataka, India. He has joined ABB India in 2017 as R\&D Engineer in Microgrid and Distributed Generation focusing on the safety design aspects of Battery Energy Storage Systems and their optimal applications. From 2015 to 2017, he was with UK based Intelligent Energy focusing on the Hydrogen Fuel Cell and Li-ion battery application for telecom and UAV sector. His research interests include application engineering of renewable energy and distributed generation, different energy storage technologies, its safety and reliability evaluation and optimization

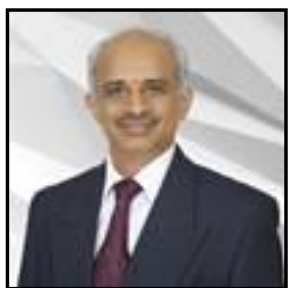

Ashoka Shyama Prasad received his Master' degree in Software Systems from BITS, Pilani and is a Bachelor degree holder from National Institute of Technology, Karnataka, India. He is working with $\mathrm{ABB}$ India and has close to 30 years of industry experience in Substation Automation especially in engineering, development of products in latest state of the art technology for protection and control of power system equipment. This also includes study of energy storage technologies in Microgrid and distributed generation. His research interests include application engineering in power system protection, different energy storage technologies, its safety and reliability evaluation and optimization. 